Farbe, die sich beim Erhitzen bis zum Verdampfen der Säure nicht verändert. Die blaue Kupferoxydammonlösung wird prachtvoll grün. Kalilauge verursacht in der wässrigen Lösung einen käsigen Niederschlag, ähnlich wie $\mathrm{H}^{3} \mathrm{~N}$, löst sich aber im Uebermass in der Kälte wieder auf. Es ist dies das gleiche Verhalten wie bei Morphin. Wird die Kalilösung zum Kochen erhitzt, so scheidet sich ein Alkaloïd in Form silberglänzender Schüppchen aus. Dieses Alkaloïd löst sich in kalter Kalilauge leicht, wird beim Erwärmen unverändert, aber in einem anderen Zustande daraus gefällt. Das amorphe Alkaloïd verwandelt sich in silberglänzende Schuppen. Es bläut Jodsäure-Amylum und redncirt Silbersalpeter in der Wärme energisch. Platinchlorid giebt ein hellgelbes Platinsalz. Verdünnte $\mathrm{SO}^{3}$ bringt in der salzsauren Lösung einen in $\mathrm{HO}$ sehr schwer löslichen, weissen, amorphen Niederschlag der schwefelsauren Verbindung hervor.

Von Morphium unterscheidet sich dieses neue Alkaloüd durch die amorphe Fällung mit $\mathrm{H}^{3} \mathrm{~N}$, durch das Verhalten gegen $\mathrm{Fe}^{2} \mathrm{Cl}^{3}$ und Kupferoxydammon, Kalilauge, concentr. $\mathrm{SO}^{3}$ und durch die Schwerlöslichkeit der schwefelsauren Verbindung; von Apomorphin dadurch, dass sich das feuchte Alkaloïd an der Luft nicht färbt, sondern völlig unverändert bleibt. (Schwciz. Wochenschr. f. Pharm. 1873. Nr. 2. p. 12.).

C. Sch.

\title{
Quantitative Bestimmung des Emetins, des Aconitins und des Nicotins.
}

Emetin in der Rad. Ipecacuanhae bestimmt man quantitativ nach $\mathrm{O}_{\text {scar }} \mathrm{Z}$ in offesty auf folgende Weise: $15 \mathrm{~g}$. des zu untersuchenden Ipecacuanhapulvers werden mit 15 Tropfen verdünnter $\mathrm{SO}^{3}$ und soviel Alkohol von $85 \%$ übergossen, dass das Volumen des Gemenges 150 C.C. beträgt und digerirt 24 Stunden. Hierauf misst man 100 C.C. des Filtrats ab, verdamptt aus diesem den Alkohol und setzt soviel von der Mayer'schen*) titrirten Lösung des Kaliumquecksilberjodids hinzu, bis keine sogenannte Tüpfelprobe-

*) $13,546 \mathrm{~g}$. $\mathrm{HrCl}$ und $49,8 \mathrm{KJ}$ löst man in Wasser und bringt das Volum der Flüssigkeit auf 1 Litor; 1 C.C. dieser $1 / 10$ normalen Titrirflüssigkeit fält $1 / 10000$ und $1 / 20000$ vom Aequivalentgewicht der Alkaloüdo. 
Rcaction meh" wahrzunehmen ist. *) Diese Reaction, eine locale 'Trübun; ganz dentlich. Ist der Titerversuch seinem Ende nahe, so muss man $20-30$ Secunden warten, ehe die Reaction eintritt. Wm keiren Verlust zu erleiden, giebt man nach beendigter Reaction Filter und Filtrat zur untersuchenden Flïssigkeit zurück Die Zahl der verbrauchten C.C. multiplicirt man mit 0,016:9 (1/10000 v. Aeq. d. Emetin) und giebt so den Gehalt von $1 \mathrm{C}$ g. Wurzel an. - Ipecacuanhawein lässt sich cbenso scharf titriren, wenn der Alkohol aus einem bestimmten Volumen vorher entfernt wird.

Zur Bestimmung des Aconitingehalts verfährt man so, dass man sich ebenfalls einen spirituösen Auszug macht, von dem 10 C.C. 1 g. der Drogue entsprechen, bereitet, oin bestimmte: Volumen von Alkohol verdampft, die erforderliche Meng's Titerflüssigkeit zusetzt und nach dem Titriren das Volum der Flïssigkeit verdampft. Die Zahl der verbrauchten D.C. des Reagens mit 0,02665 (1/20000 des Aq. d. Aconitins) mit dem Product aus dem Volum der nach den Titriren gemessenen Flüssigkeit multiplicirt und 0,00005 addirt, ergiebt das in der Flüssigkeit befindliche Aconitin. Nach diesem Verfahren stellt sich der Aconitingehalt von Aconitum Stotrkeanum, gesammelt wo die Blüthenknospen zwar entwickslt, aber noch nicht aufgeblüht waren, auf $0,1699 \%$, der des Stengels auf $0,1166 \%$, der der frischen Blätter auf 0,34188 ; derjenige der Blätter von Aconitum Napellus, zu derselben Zeit gresammelt, auf $0,1776 \%$, der des Stengels suf $0,1236 \%$, der der Blüthe anf $0,435 \%$. Aconitum varingatum, um dieselbe Zeit gesammelt, gab einen Alkaloïdgehalt von $0,167 \%$ für die Blätter, von $0,1009 \%$ fiur den Stengel und von $0,435 \%$ für die Blüthe. In Aconitum Stoerkeanum, bei entwickelter Blüthe gesammelt, betrug der Alkaloïdgeaalt der Blätter $0,271 \%$, des Stengels $0,277 \%$ und der Blïthen 0,7294\%. Der grössere Reichthum der Blüthen an Aconitin ist sehr deutlich.

Nicotin lässt sich, da aus dem Tabak durch das Reagens nichts weiter gefällt wird, ebenfalls auf massanalytischem Wege mittelst Kaliumquecksilberjodid recht gut bestimmen. M.an nimmt $15 \mathrm{~g}$. des zu untersuchenden zerklei-

*) Durch eiı Filırum von ca. $3 \mathrm{~cm}$. Durchmesser lässt man einige Tropfen in ein Uhrglas fallen, was auf schwarzem Papier steht, und tupft mit einem, in Kaliumquecksilberjodid getauchten Glasstäbchen ins Filtrat. 
nerten Tabaks, versetze ihn mit 15 Tropfen verdiunnter $\mathrm{SO}^{2}$ und soviel Alkohol von $85 \%$, dass das Volum des Ganzen 150 C.C. beträgt, digerire 24 Stunden, filtrire, verdunste aus 50 C.C. vom Filtrat den Alkohol, um dann die nöthige Menge Reagens der noch trüben Flüssigkeit zuzusetzen. Dio Zahl der verbrauchten C. C. des verbranchten Reagens multiplicirt mit 0,00105 (1/10000 Aeq. Nicotin) giebt den Nicotingehalt von 5. g. Tabak an. (Oscar Zinotfsky, dic quantitative Bestimmung des Emetins, des Aconitins und des Nikotens. Dorpat 1872, a. demselb. Neues Jahrbuch f. Pharmacie. Bd. XXXVIII. S. 334.).

C. Sch.

\section{Das Koussin.}

Schon Pavesi untersuchte das Kousso auf seine Bestandtheile, wobei er einen harzartigen Körpor fand, den er Koussin nennt und von welchem er glaubte, dass or sich nur in den Pollen finde.

Dr. C. Bedall hat nun neuerdings dieses Capitel ebenfalls wieder aufgegriffen und getunden, dass das von Pavesi als wirksamer Bestandtheil der Koussoblätter angenommene Koussin nicht nur in den Bliithen, sondern anch in den Stengeln und Blättern vorkömmt, wenn auch in geringerer Menge. Bedall kehrte nach den verschiedensten Versuchen und Methoden zu der Pavesischen Darstellungsweise zurück, die der Darstellungsweise des Santonins analog ist. Die Koussoblïthen werden durch wiederboltes Behandeln mit Alkohol unter Kalkhydratzusatz erschöpft und der Rückstand mit Wasser gekocht. Sämmtliche Auszüge werden gemischt, vom Filtrat der Weingeist abdestillirt und mit Essigsäure gefällt, wobei das Koussin als weisser flockiger Niederschlag zu Boden fällt, wo es sehr bald zusammensintert und harzartig zusammenklebt. Beim Trockenen selbst in sehr gelinder Wärme wird es mehr oder weniger gelb, bei höherer Temperatur sogar leicht braun. Ein vorsichtig bereitetes und getrocknetes Präparat stellt ein in geringer Menge geruchloses, in grössern Quantitäten jedoch eigenthïmlich nach Juchten riechendes, anhaltend bitter und kratzend sehmeckendes Pulver von mehr oder weniger gelblicher oder gelblich weisser Farbe dar. Unter dem Mikroskop zeigt es krystallinische Theilchen ohne bestinnte Krystallform. Es ist in Wasser 